\title{
The Foamed Metal Structures in Numerical Testing
}

\author{
Antoni JOHN*, Malgorzata JOHN**, Jarosław BRODNY*** \\ *Silesian University of Technology, Faculty of Mechanical Engineering, Konarskiego 18A, 44-100 Gliwice, Poland, \\ E-mail: antoni.john@polsl.pl \\ **Silesian University of Technology, Faculty of Mechanical Engineering, Konarskiego 18A, 44-100 Gliwice, Poland, \\ E-mail: malgorzata..john@polsl.pl \\ ***Silesian University of Technology, Faculty of Organization and Management, Roosevelta 26-28, 41-800 Zabrze, \\ Poland, E-mail: jaroslaw.brodny@polsl.pl
}

crossref http://dx.doi.org/10.5755/j01.mech.24.1.20213

\section{Introduction}

In the recent years, in the design of new materials researchers try to find materials which have lower densities and good mechanical properties. We can denote all kinds of composite materials and highly porous. Highly porous materials have in their structure a cavity (cells) filled with gas. These structures are formed from different types of materials from the group of metals, polymers and ceramics. Foamed metals are pure metals or alloys that have in their structure a significant amount of intentionally introduced gas bubbles (ERG [1], Yu and Banhart [2], Andersen [3]). We can denote that expanded metal is used often as components of a vibration damping or impact-absorbing casing. This is due to the high energy absorption property of the metal foam, many times larger than the native material (Sobczak [4], Ashby [5]).

The foam metal structures are used in many types of machine tools for impact protection as vibration isolators, in other equipment and sometimes components (ISOTECH, inc. [6]). An example of advanced use of a metal foam may be a new type of gears into which the elements of expanded metal between the hub and the ring gear which reduces the noise throughout the transmission, and reduces the impact of the teeth themselves and the weight of the mix (Hansena [7], Oczoś [8]). Many applications one can observe in automotive, wherein the foam metal used to reinforce the hollow profile in the design of safe crumple zones (Havel metal foam [9]). Crumple zones safe are responsible for absorbing the energy created during impact.

In the literature we can find many papers on the metal foam but only a few of them concerns the numerical simulation. Most of these concern the fluid flow in porous materials (Boomsma at al. [10], Dukhan [11], Mudunuri at al. [12]) or heat transfer (Calmidi and Mahajan [13], Kopanidis at al. [14]). Modeling is focused on the structure with open cells De Jaeger at al. [15] present numerical model as trabecular structure. Sadovskaya [16] presents numerical simulation of deformation of a metal foam but in the theoretical domain only.

One can find in the literature works using numerical homogenization of the bone scaffold structures (Beluch at al. [17]) of materials with internal cracks (Czyż at al. [18]) or in analysis of composite with inclusions (Makowski at al. [19]). Most of this works was based on homogenization of the RVE 2D models.

In the work a new approach to the modeling of the metal foam is presented. It consists of closed cells ballshaped and cylindrical voids and represented by means of
RVE elements with different number, size and distribution of the pores (voids). Numerical homogenization method is applied to calculate material coefficient matrix of simulated structures.

In earlier study developed 3D model of RVE elements and the coefficients of elasticity matrix were determined for different number and size of voids and their various positions. It means that influence of geometrical features on material parameters was tested.

Using results obtained from numerical homogenization a numerical simulation of three-point bending test was proposed. Sample used in a test was prepared as a sandwich structure where core and claddings were made from pure aluminium and a hollow profile filled with metal foam. During the test it was investigated the effect a change in thickness of the core and claddings on the displacement and stresses values. Displacement and stresses have been shown with respect to the total weight of tested sample.

The aim of the work is: how can we influence on material parameters and mechanical properties (stress and displacement) in foamed metal structures and how easy and simple numerical simulations can be made.

\section{Numerical homogenization}

Numerical homogenization is used for calculating the variables defining the status and parameters of the microstructure in such a way that by using these variables it can be modelled macrostructure materials in such a way as if it was made of homogeneous material, a phenomenon occurring in the microstructure which affect the macrostructure are represented by the calculated variables (Kouznetsova [20], Zohdi [21]). The advantages of this method are presented below:

- no need putting requirements in relation to assumptions of constitutive centre macroscopic,

- allows the consideration of large deformations in both micro and macro,

- makes it possible to use any of the techniques of numerical calculation in both scales,

- the ability to modify the micro to the macro level of analysis,

- the possibility of using the issues of dynamic and non-linear.

The elements which represent the structure of the micro call RVE (representative volume element). RVE models should represent the micro-structure to the extent possible to identify the properties of the medium in composition. It is important RVE small enough to make it simple 
as possible so that we can carry out its detailed analysis, yet large enough to be able to represent the microscopic structure of the tested structure. There are three types of approaches to the use RVE. Here, the adoption of a constitutive law at the macro level, testing of material parameters is applied. The methodology is the same as in the classic approach, which is performed six studies with six different boundary conditions, and then averages the strain and stress in a model using the following equations:

$$
\begin{aligned}
& \left(\varepsilon_{i j}\right)=\frac{1}{V_{R V E}} \int_{V_{R V E}} \varepsilon_{i j} d V_{R V E}, \\
& \left(\sigma_{i j}\right)=\frac{1}{V_{R V E}} \int_{V_{R V E}} \sigma_{i j} d V_{R V E},
\end{aligned}
$$

where: $\left\langle\varepsilon_{i j}\right\rangle,\left\langle\sigma_{i j}\right\rangle$ are averaged strain and stress at macro scale respectively, $V_{R V E}$ is volume of RVE element.

Next when these values $\left\langle\varepsilon_{i j}\right\rangle$, $\left\langle\sigma_{i j}\right\rangle$ are designated we substitute them into a matrix in equation (3) and then it is possible to calculate elasticity matrix $C$ of equivalent homogenous material using the matrix Eq. (4).

$$
\begin{aligned}
& {\left[\begin{array}{c}
\left(\sigma_{11}\right) \\
\left(\sigma_{22}\right) \\
\left(\sigma_{33}\right) \\
\left(\sigma_{23}\right) \\
\left(\sigma_{13}\right) \\
\left(\sigma_{12}\right)
\end{array}\right]=\left[\begin{array}{llllll}
C_{11} & C_{12} & C_{13} & C_{14} & C_{15} & C_{16} \\
& C_{22} & C_{23} & C_{24} & C_{25} & C_{26} \\
& & C_{33} & C_{34} & C_{35} & C_{36} \\
& & & C_{44} & C_{45} & C_{46} \\
& & & & C_{55} & C_{56} \\
& \text { Sym... } & & & & C_{66}
\end{array}\right] *\left[\begin{array}{c}
\left(\varepsilon_{11}\right) \\
\left(\varepsilon_{12}\right) \\
\left(\varepsilon_{13}\right) \\
\left(\varepsilon_{14}\right) \\
\left(\varepsilon_{15}\right) \\
\left(\varepsilon_{16}\right)
\end{array}\right],} \\
& c=\left(\sigma_{i j}\right) *\left(\varepsilon_{i j}\right)^{-1} .
\end{aligned}
$$

The simplified models of foam metal structures were prepared using FEM. The MSC Software system was used. In RVE elements the size of voids, the number of voids (density) and position were changed. As a basic material assumed pure aluminum with linear elastic properties: Young modulus $E=69 \mathrm{GPa}$, Poisson ratio $v=0.33$. During numerical simulations 13 models of RVE elements were prepared (Table 1).

Each RVE element was modeled as a cube measuring $5 \times 5 \times 5 \mathrm{~mm}$. The simplest element had one void with a radius of $2.25 \mathrm{~mm}$ centrally positioned (No. 1). The next four RVE elements are regular, further 5 elements are irregular and 3 last elements are with cylindrical voids. The examples of each type of RVE elements presented in Table 1 are showed in Fig. 1.

As a result of numerical analysis the values of the stresses and strains per each item were obtained. Next, the value of the integral Eqs. (1) and (2) were determined numerically and divided by the volume. As a result of this operation matrix medium stress and strain are obtained and then using the formula (4) the elasticity matrix of defined materials can be determined. Selected results for regular RVE models are shown in Eq. (5), for irregular RVE models in Eq. (6). Positions of material coefficients correspond to matrix $C$ in Eq. (3). It can be observed that for regular RVE models that system of elasticity matrix tends to the isotropic structure. The more voids that convergence is improved. For irregular RVE models designated elasticity matrix is full and asymmetrical. The number, size and location of the voids significantly effects on the shape of the elasticity matrix and value of designated coefficients. More details concern numerical calculations and final form of the elasticity matrix for another RVE elements one can find in [22, 23] and $[24,25]$.

Table 1

Description of RVE elements

\begin{tabular}{|c|c|c|}
\hline $\begin{array}{c}\text { Number } \\
\text { of model }\end{array}$ & Density $\left[\mathrm{g} / \mathrm{mm}^{3}\right]$ & $\begin{array}{c}\text { Number } \\
\text { of voids }\end{array}$ \\
\hline 1 & 1.6818 & 1 \\
\hline 2 & 1.7495 & 8 \\
\hline 3 & 2.0506 & 21 \\
\hline 4 & 2.0133 & 121 \\
\hline 5 & 1.9587 & 1044 \\
\hline 6 & 2.2114 & 4 \\
\hline 7 & 2.1729 & 8 \\
\hline 8 & 1.8212 & 8 \\
\hline 9 & 2.0667 & 14 \\
\hline 10 & 2.4334 & 80 \\
\hline 11 & 1.2389 & 18 \\
\hline 12 & 1.3489 & 16 \\
\hline 13 & 1.6918 & 12 \\
\hline
\end{tabular}

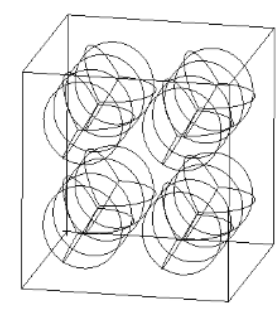

a

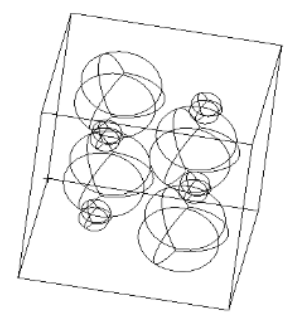

$\mathrm{b}$

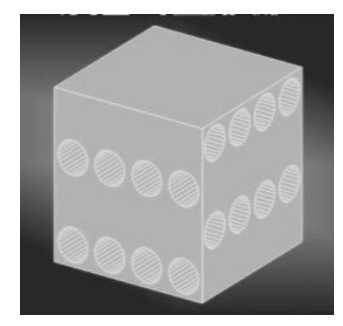

c

Fig. 1 RVE models: a -regular model 2, b-irregular model 7, c-cylindrical model 12

\section{Numerical examples}

Prepared models of foamed metal structure are used in sandwich structures. For testing the mechanical parameters of sandwich structures numerical simulation of three point bending test was performed. The sample with a 
length of $220 \mathrm{~mm}$, a height of $30 \mathrm{~mm}$ and $50 \mathrm{~mm}$ wide was modelled (Fig. 2). The sample is oriented relative to the reference so that the axis " $\mathrm{Z}$ " indicates the length of the sample and the axis " $Y$ " the height (thickness). Cladding and core were made from pure aluminium (Young modulus $69 \mathrm{GPa}$, Poisson's ratio 0.33). Acting force equals 100 N. 8-nodes hexagonal finite elements with substitute material parameters (from homogenization) were used.

The first test was investigated the effect a change in thickness of the claddings at a constant thickness of the core on the displacement and stresses values. Figs. 3 and 4 show obtained results. In the next step thickness of the claddings was constant and a thickness of the core changed. The results are presented in Figs. 5 and 6. Displacement and stress values are shown on the total weight of the system under study.

In the first case, it was observed that increasing the share of the claddings increases the rigidity of the structure, but the layer is thicker the rapidly increasing mass model.

$$
C_{i j}=\left[\begin{array}{cccccc}
66736.5 & 33468.4 & 33468.4 & -0.0 & -0.0 & 0.0 \\
33468.4 & 66736.4 & 33468.4 & -0.0 & -0.1 & 0.0 \\
33468.4 & 33468.4 & 66736.5 & -0.0 & -0.1 & -0.0 \\
-0.0 & 0.0 & 0.0 & 33268.0 & 0.0 & -0.0 \\
-0.0 & -0.0 & -0.0 & 0.0 & 33268.04 & 0.0 \\
0.0 & 0.0 & 0.0 & 0.0 & 0.0 & 33268.0
\end{array}\right] \text {, }
$$

$$
C_{i j}=\left[\begin{array}{cccccc}
84269.5 & 39025.7 & 44202.9 & -47.1 & 5036.4 & 86.4 \\
44607.7 & 83538.3 & 46846.3 & -49.9 & 5337.5 & 91.5 \\
37726.5 & 34979.4 & 81798.7 & -42.3 & 4514.2 & 77.4 \\
-473.1 & -438.6 & -496.8 & 42179.3 & -56.5 & -0.9 \\
-2130.2 & -1975.1 & -2237.1 & 2.3 & 41923.9 & -4.3 \\
-515.9 & -478.3 & -541.8 & 0.5 & -61.7 & 42177.7
\end{array}\right] .
$$

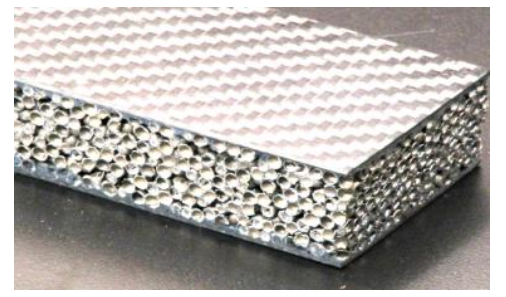

a

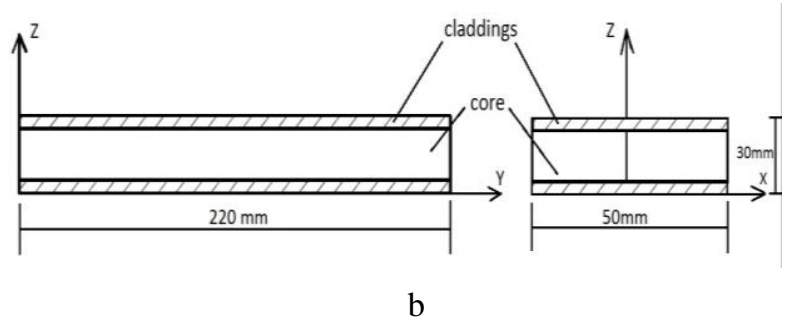

Fig. 2 The sandwich structure filling of metal foam [6] (a) and the schema of tested sandwich structure (b)

In the second case it was found that, at constant thickness of claddings $(2 \mathrm{~mm})$ too greatly increasing the thickness of the foam layer (over $20 \mathrm{~mm}$ ) is uneconomical because it does not introduce any significant changes in the properties of the structure.

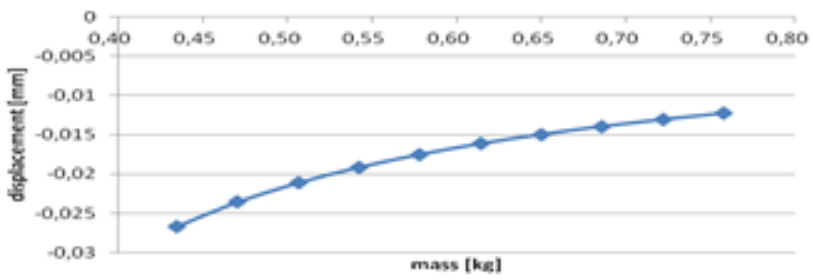

Fig. 3 The maximum displacement of structure as a function of the mass with the constant thickness of the core

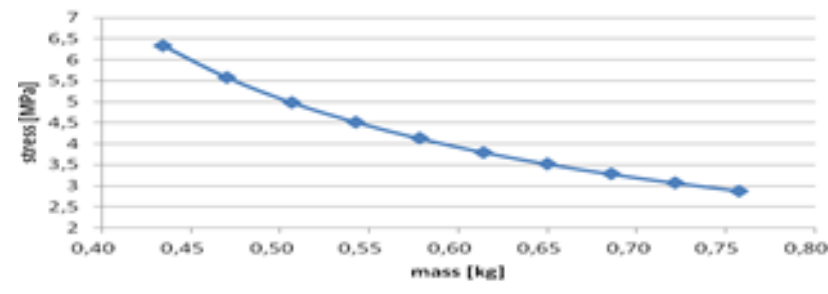

Fig. 4 The maximum stresses of structure as a function of the mass with the constant thickness of the core

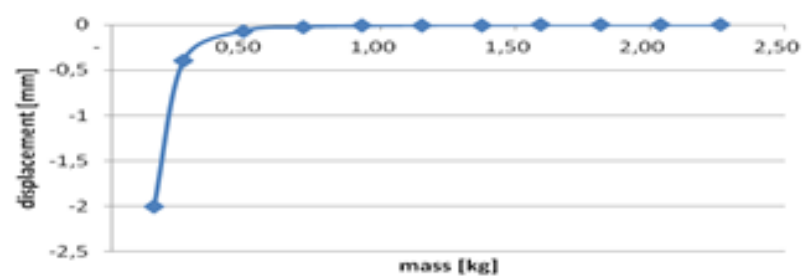

Fig. 5 The maximum displacement of structure as a function of the mass with the constant thickness of the claddings

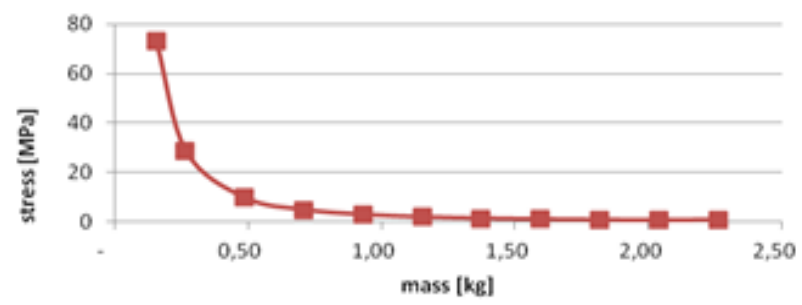

Fig. 6 The maximum stresses of structure as a function of the mass with the constant thickness of the claddings

In the final stage to investigate how foam structures behave under the influence of twisting loads, numerical simulations of axial torsion test of the foam filled profile was 
performed. The modelled section has two axes of symmetry. The real existing hollow profile and the scheme of boundary conditions in the test presents Fig. 7.

During the numerical tests of torsion of foamed profile in all cases, the sample cross section area was 90 mm2. Tests were conducted for different combinations of foam layer thickness and coating. The obtained results were compared to assess the effect of the thickness ratio of the individual layers and to what extent the thickness of the claddings was profitable.

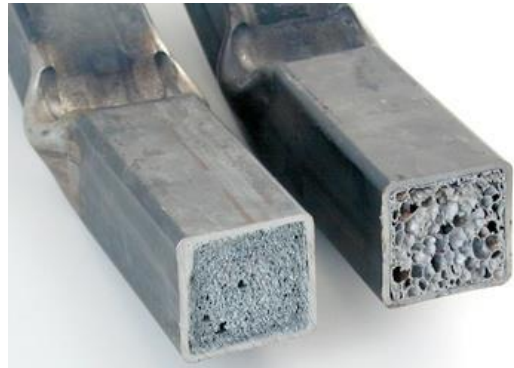

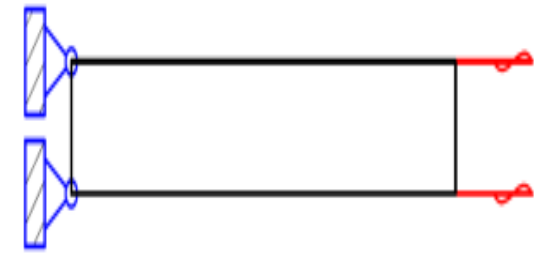

b

Fig. 7 Profile of filling foam [9] (a) and boundary conditions in simulation of torsion test (b)

The magnitude displacements for selected thickness of claddings are presented in Figs. 8, 10 and 12. The stress distribution for the same selected thickness of claddings are presented in Figs. 9, 11 and 13, respectively.

As one can see the distribution of displacement in the model is similar and does not depend on the thickness of the linings. It has been noted, however, that the stresses are concentrated in the walls of the profile, so it can be inferred that they are the ones that carry the largest part of the load.

Patran 2013 26-Mar-16 1259.58

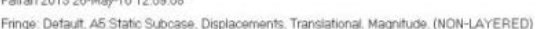

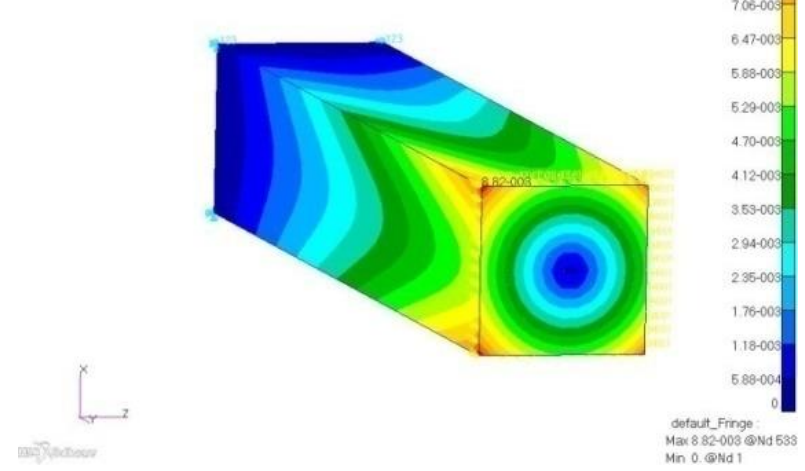

Fig. 8 Torsion - profile of filling foam, thickness of claddings $0.25 \mathrm{~mm}$ : displacement (in $\mathrm{mm}$ )

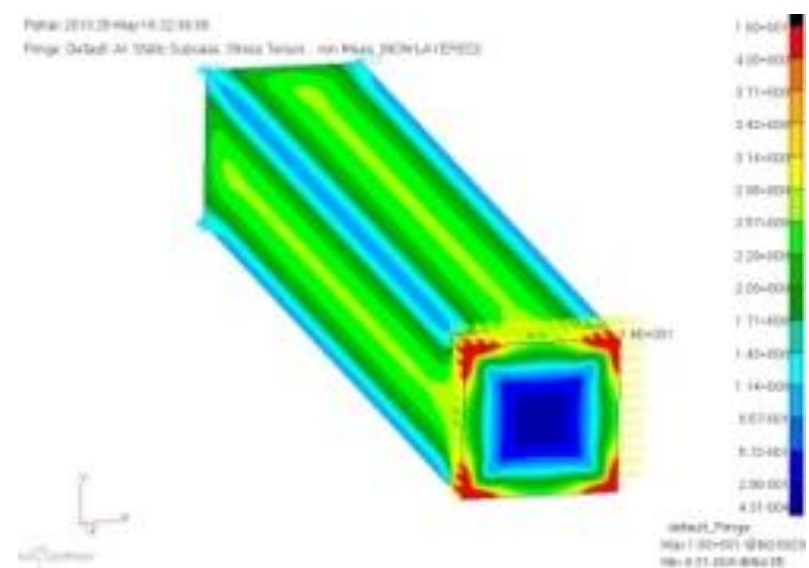

Fig. 9 Torsion - profile of filling foam, thickness of claddings $0.25 \mathrm{~mm}$ : stresses (in $\mathrm{MPa}$ )

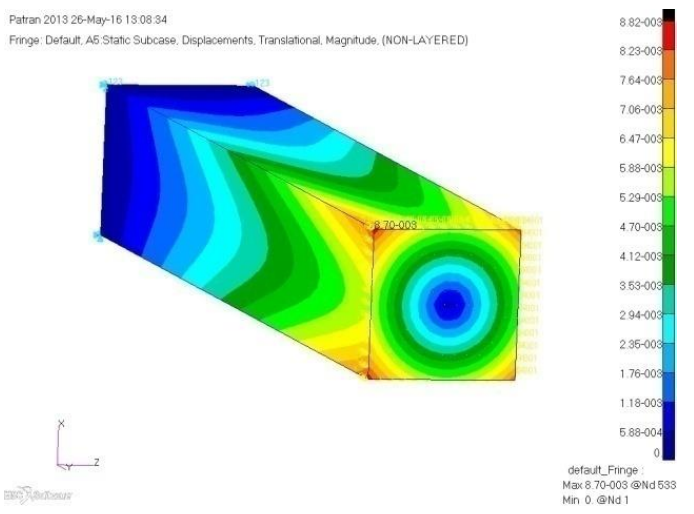

Fig. 10 Torsion - profile of filling foam, thickness of claddings $1 \mathrm{~mm}$ : displacement (in $\mathrm{mm}$ )

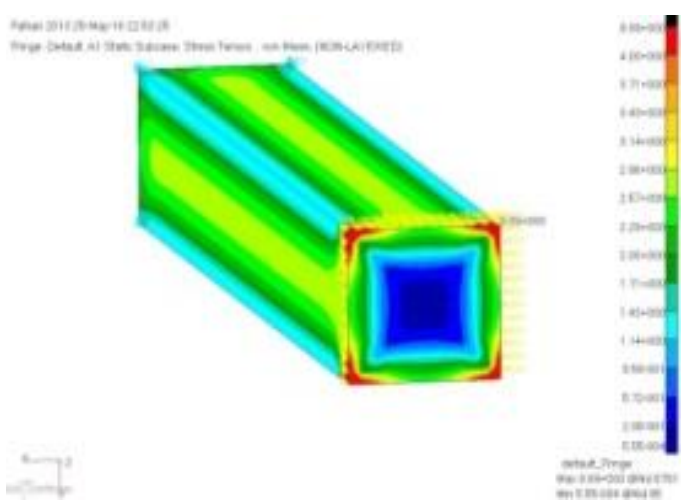

Fig. 11 Torsion - profile of filling foam, thickness of claddings $1 \mathrm{~mm}$ : stresses (in MPa)

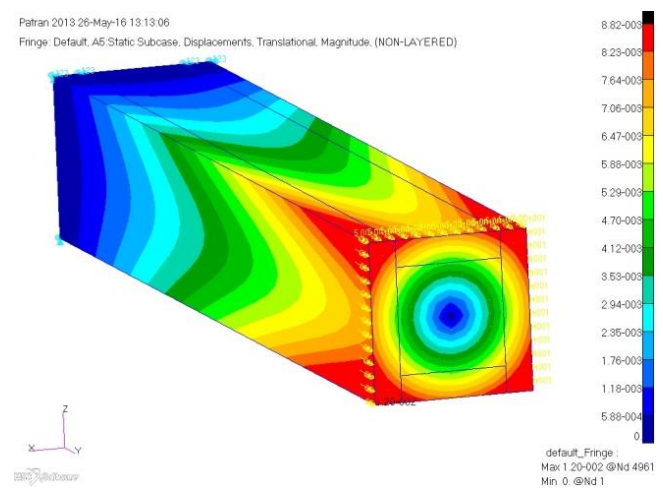

Fig. 12 Torsion - profile of filling foam, thickness of claddings $5 \mathrm{~mm}$ : displacement (in $\mathrm{mm}$ ) 


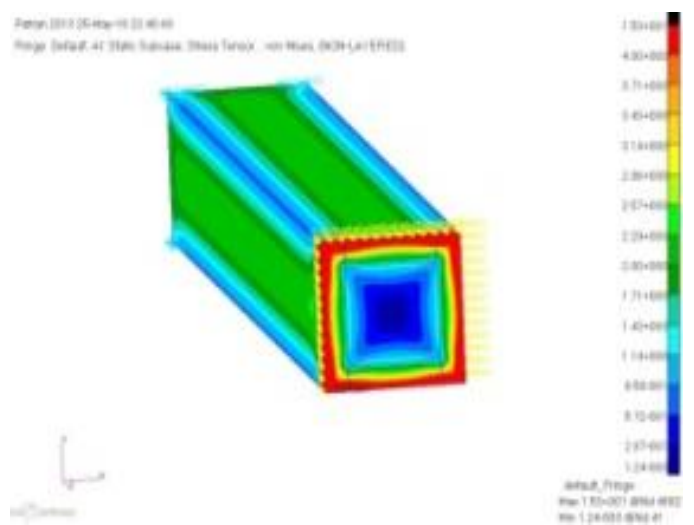

Fig. 13 Torsion - profile of filling foam, thickness of claddings $5 \mathrm{~mm}$ : stresses (in $\mathrm{MPa}$ )

\section{Conclusions}

In the work a new approach to the modeling of the metal foam consists of closed cells and represented by means of RVE elements with different number, size and distribution of the pores is presented. Numerical homogenization method is applied to calculate material coefficient matrix of simulated structures.

Here, the influence of geometrical features on material parameters was tested. It can be observed that if the inclusions grid is regular then density primarily influence on coefficient of elasticity matrix $\mathrm{C}$.

In general, it was found that during three point bending test the increasing the thickness of the cladding leads to the effect that the core is minimized and the stresses and displacements tend to a certain characteristic values.

During the numerical tests of torsion, we can observe typical behavior for torsion - the stresses are concentrated in the walls of the profile. As stiffness grows - stress also increases.

In further studies, the results (material constants) will be used to develop and stress analysis of complex systems containing elements made of foamed metal type structures. This approach should result in significantly shorten the time of calculation.

In the next step it is also planned to make samples using 3D printing and perform experimental testing (threepoint bending test and compression test simulated also numerically).

\section{References}

1. ERG Aerospace Corporation. 2016. Material-Applications-guide. [accessed 9 March 2016]. Available from Internet: http://www.ergaerospace.com/Material-Applications-guide.html.

2. C. Yu J. Banhart, 1998. Mechanical Properties of Metallic Foams, IFAM [accessed 9 March. 2016]. Available from Internet: http://www.helmholtz-berlin.de/me$\mathrm{dia} /$ media/spezial/ people/banhart/html/B-Conferences/b020_yu1998.pdf.

3. Andersen O. 2016. Cellular metallic structures. Fraunhofer IFAM [accessed 9 March. 2016]. Available from Internet: (in German). http://www.ifam.fraunhofer.de/content/dam/ifam/de/documents/dd/Infobl\%C3\%A4tter/zellulare_metallische_werkstoffe_fraunhofer_ifam_dresden.pdf.
4. Sobczak, J. 2005. Highly porous materials, Foundry Research Institute Kraków, 172 p. (in Polish).

5. Ashby, M. F.2000. Metal Foam a Design Guide, Butterworth Heinemann, Boston, $456 \mathrm{p}$.

6. ISOTECH, inc. 2016. Foamed Aluminum Applications. [accessed 10 March 2016]. Available from Internet: http://www.isotechinc.com/news/ metal-foams-434.

7. Hanssena, A. G.; Girard, Y.; Olovsson, L.; Berstad, T.; Langseth, M. 2006. A numerical model for bird strike of aluminium foam-based sandwich panels, Int. Journal of Impact Engineering 32: 1127-1144. http://dx.doi.org/10.1016/j.ijimpeng.2004.09.004.

8. Oczoś, K. 2010. Aluminium foam - properties, the manufacture, use. Mechanik 5-6/2010: 309-317 (in Polish).

9. Havel metal foam. 2016. Innovative solutions for lightweight construction. Aluminium foam sandwiches and 3d mouldings. [accessed 9 March. 2016]. Available from Internet: http://www.havel-mf.de/index_en.html.

10. Boomsma, K.; Poulikakos, D.; Ventikos, Y. 2003. Simulations of flow through open cell metal foams usingan idealized periodic cell structure, International Journal of Heat and Fluid Flow 24: 825-834. http://doi.org/10.1016/j.ijheatfluidflow.2003.08.002.

11. Dukhan, N. 2013. Metal Foam: Fundamentals and Applications. DEStech Publications, Inc., Lancaster, Pensylvania USA, p.423.

12. Mudunuri, V. R.; Sudhini, G.; Fakheri, A. 2010. Analytical and Experimental Investigations of High Porosity Metallic Foams, Fluid Flow, Heat Transfer and Thermal Systems, Parts A and B, 7: 229-236. http://dx.doi.org/10.1115/IMECE2010-39749.

13. Calmidi, V.V.; Mahajan, R.L. 2000. Forced Convection in High Porosity Metal Foams, J. Heat Transfer 122(3): 557-565. http://dx.doi.org/10.1115/1.1287793.

14. Kopanidis, A.; Theodorakakos, A.; Gavaises, E.; Bouris, D. 2010. 3D numerical simulation of flow and conjugate heat transfer through a pore scale model of high porosity open cell metal foam, International Journal of Heat and Mass Transfer 53: 2539-2550. http://dx.doi.org/10.1016/j.ijheatmasstransfer.2009.12.067.

15. De Jaeger, P.; T'Joen, P.; Huisseune, H.; Ameel, B.; De Paepe, M. 2011. An experimentally validated and parameterized periodic unit-cell reconstruction of opencell foams, J. Appl. Phys.109: 103519. http://dx.doi.org/10.1063/1.3587159.

16. Sadovskaya, O.V. 2013. Numerical simulation of deformation of a metal foam, Proceedings of XLI International Summer School-Conference APM, 485-491.

17. Beluch, W.; Burczyński, T.; Długosz, A. 2007. Evolutionary multi-objective optimization of hybrid laminates, Computer Assisted Mechanics and Engineering Sciences, 14(4): 569-578.

18. Czyż, T.; Dziadkiewicz, G.; Fedeliński, P.; Górski, R.; Ptaszny, J. 2013. Advanced computer modelling in micromechanics, Publisher Silesian University of Technology, Gliwice, $132 \mathrm{p}$.

19. Makowski, P.; John, A.; Kuś, W.; Kokot, G. 2013. Multiscale modeling of the simplified trabecular bone structure, Mechanika, Proc. of the $18^{\text {th }}$ Int. Conf. Mechanika 2013, Kaunas: 156-161.

20. Kouznetsova, V.G., Geers, M.G.D., Brekelmans, V.A.M. 2004. Multi-scale second-order computational 
homogenization of multi-phase materials: a nested finite element solution strategy, Comput. Methods Appl. Mech. Eng. 194: 5525-5550.

https://doi.org/10.1016/j.cma.2003.12.073.

21. Zohdi, I.T. 2004. Homogenization Methods and Multiscale Modeling, Encyclopedia of Computational Mechanics, Solids and Structures. John Wiley \& Sons 407430.

22. John, A.; John, M.; Bartela, A. 2016. Numerical homogenization of the foamed metal structures. Mechanika 22(5): 343-348.

http://dx.doi.org/10.5755/j01.mech.22.5.16689.

23. John, A.; John, M. 2016. Foam metal and honeycomb structures in numerical simulation, ANNALS of Faculty Engineering Hunedoara, International Journal of Engineering, T. XIV, 4: 27-32.

24. John, A.; John, M.; Brodny, J. 2017. Numerical testing of the foamed metal structures, Proc. of the 22th Int. Conf. Mechanika 2017, Kaunas: 152-158.

25. John, A.; John, M.; Bartela, A. 2016. Numerical simulation of the foamed metal structures, Proc. of the $6^{\text {th }}$ ICTD, $5^{\text {th }}$ CMMNO Gliwice 2016, Abstracts, 53.
A. John, M. John, J. Brodny

THE FOAMED METAL STRUCTURES IN NUMERICAL TESTING

S u m m a r y

In the paper numerical simulation of the foamed metal structures using numerical homogenization algorithm is prescribed. The first, numerical model of heterogeneous porous simplified structures of typical foamed metal, based on the FEM was built and material parameters (coefficients of elasticity matrix of the considered structure) were determined with use of numerical homogenization algorithm. In the work the different RVE models of structure were created and their properties were compared at different relative density, different numbers and the size and structure of the arrangement of voids. Finally, obtained results were used in modeling of typical elements made from foam metals structures - sandwich structures and hollow profiles filling with metal foam. Three point bending test was performed for sandwich structures. Simulation were done for different dimensions of cladding and core. Additionally, the torsion test was performed for profiles filling with metal foam. Typical behavior for torsion was observed.

Keywords: foam metal structures, multi-scale modelling, numerical homogenization, RVE, FEM, sandwich structure.

Received July 25, 2017

Accepted February 15, 2018 